\title{
ENTRE A ALDEIA E A CIDADE: O TRABALHO NA PERSPECTIVA DOS ÍNDIOS GUARANI E KAINGANG DO SUDOESTE DO PARANÁ NA LUTA PELA SOBREVIVÊNCIA
}

\author{
BETWEEN THE VILLAGE AND THE CITY: THE WORK \\ FROM THE PERSPECTIVE OF THE GUARANI AND \\ KAINGANG SOUTHWEST PARANÁ IN THE FIGHT FOR \\ SURVIVAL
}

\author{
Marta Beatriz dos Santos Dall' Igna*
}

\begin{abstract}
RESUMO
O objeto estudo parte do pressuposto da urgência de compreender o porquê de as tribos Guarani e Kaingang - reserva de Mangueirinha sudoeste Paraná - estão migrando para cidades vizinhas em busca de trabalho. Partindo da (pesquisa etnográfica) em observação direta e indireta na reserva indígena e com empresas empregadoras a fim de descrever e interpretar os processos interculturais entre sociedades indígenas e o homem branco. Na perspectiva marxista de "trabalho produtivo" o modelo capitalista com o objetivo de produzir lucro - não encontra espaço e função na interpretação das sociedades indígenas - enquanto estejam isoladas ou não, sendo marginalizadas ao sistema capitalista. Para isso elegeuse autores como: Marx, Clastres, Mészaros, e Frigotto. Deste modo, surge o campo híbrido, fluido, polissêmico, ao mesmo tempo promissor das formas diferenciadas de trabalho e como isso se representa socialmente. Identificar esses distintos sujeitos e das suas múltiplas identidades socioculturais em meio a suas representações sociais pela sobrevivência.
\end{abstract}

Palavras-chave: Trabalho. Estado. Sociedades Indígenas. Pobreza.

\begin{abstract}
The study object assumes the understanding urgency why the Guarani's and Kaingang's tribes from Mangueirinha reservation in Paraná southwest are migrating to nearby towns in order to search for work. Starting from the (ethnographic research) in direct and indirect observation on the Indian reservation and business employers in order to describe and interpret intercultural processes among indigenous societies and the pale man. In the Marxist perspective, the "productive work" in the capitalist model with the goal of producing a profit - no place and function in the interpretation of indigenous societies as are isolated or not being marginalized in the capitalist system. As a result of such perspective, he was elected as authors: Marx, Clastres, Meszaros, and Frigotto. Thus, he arises the hybrid, fluid, polysemic, while promising to the
\end{abstract}

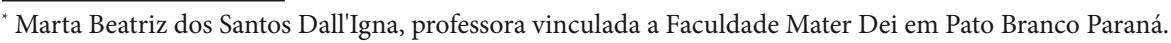


ways of differentiated work and how it is socially as well. It is also considered the identification of these different subjects and his multiple sociocultural identities amid the social representations for survival.

Keywords: Labor. State. Indigenous and societies and poverty.

\section{Introdução}

Problematizar uma discussão acerca do trabalho na perspectiva do olhar para a condição de pobreza que vive o contingente humano requer um exercício duplo por parte do pesquisador. Primeiro, ter a realidade presente como uma causa em defesa. Segundo, trazer à tona as teorias clássicas que revelam através da ontologia, a relação indissociável em homem e natureza, o que consequentemente desencadeia o trabalho.

Ao se tratar da ontologia do trabalho na perspectiva das sociedades indígenas há que se partir da clareza de três premissas básicas que antevêm o estudo.

1. O que é que reconhecemos como "trabalho" nas sociedades indígenas; 2. Como são interpretadas as perspectivas de trabalho pela sociedade capitalista, 3. Como as sociedades indígenas entendem o trabalho em relação ao que nós definimos como "trabalho".

Partindo dessas questões-problema, é possível a reflexão, e, faz-se necessário retomar a noção de "trabalho" em estudos clássicos.

\section{Homem e Trabalho}

"Assim como o indivíduo não está sozinho no grupo e cada sociedade não está sozinha entre as outras, o homem não está só no universo"

(LÉVI-STRAUSS,1996).

O Trabalho e reprodução vistos em duas categorias que compõe uma determinação reflexiva: não há trabalho que não seja um ato de reprodução da sociedade, e, por outro lado, sem o trabalho nenhuma reprodução social seria possível. São duas categorias ontologicamente articuladas e rigorosamente indissociáveis. Esta articulação tão íntima entre estas categorias faz como que, no estudo dos casos singulares da práxis social, muitas vezes não pos- samos distinguir, a não ser por uma análise muito particularizada, um ato de trabalho de um ato pertencente à esfera da reprodução social.

Engels enfatizou que o trabalho, muito mais do que "fonte de toda a riqueza" é "a condição básica e fundamental de toda a vida humana" (Engels [1876] 1977: 63).

Marx é distinto ao se referir, para entendermos o que é trabalho, temos inicialmente de considerar o processo de trabalho à parte de qualquer estrutura social determinada.

Antes de tudo, o trabalho é um processo de que participam o homem e a natureza, processo em que o ser humano com sua própria ação, impulsiona, regula e controla seu intercâmbio material com a natureza. Defronta-se com uma de suas forças. Por em movimento as forças naturais de seu corpo, braços e pernas, cabeça e mãos, a fim de apropriar-se dos recursos da natureza, imprimindo-lhes forma útil à vida humana. Atuando assim sobre a natureza externa e modificando-a, ao mesmo tempo modifica sua própria natureza ${ }^{1}$.

Na sequência, Marx dá outro exemplo de forma metafórica, sobre o que diferencia o homem dos animais visto no processo do trabalho:

Uma aranha executa operações semelhantes as do tecelão, e a abelha supera mais de um arquiteto ao construir sua colmeia. Mas o que distingue o pior arquiteto da melhor abelha é que ele figura na mente sua construção antes de transformá-la em realidade. No fim do processo do trabalho aparece um resultado que já existia antes idealmente na imaginação do trabalhador. Ele não transforma apenas o material sobre o qual opera; ele imprime ao material o projeto que tinha conscientemente em mira, o qual constitui a lei determinante do seu modo de operar e ao qual tem de subordinar sua vontade $^{2}$.

\footnotetext{
${ }^{1}$ O Capital, I, cap, V, p. 202.

${ }^{2} \mathrm{O}$ capital, I cap. V, p. 202. Marx nesta passagem procura explicar que nesse processo o homem "submete ao seu domínio o jogo das forças naturais".
} 
Tal distinção proposta por Marx em O Capital, livro I, vai avançando a compreensão de tal forma que define o "trabalho útil" como:

No processo de trabalho, a atividade do homem opera uma transformação, subordinada a um determinado fim, no objeto sobre que atua por meio do instrumental de trabalho. $\mathrm{O}$ processo extingue-se ao concluir-se o produto. $\mathrm{O}$ produto é um valor-de-uso, um material da natureza adaptado às necessidades humanas através da mudança da forma. O trabalho está incorporado ao objeto sobre o que atuou ${ }^{3}$.

Nesta outra passagem Marx evidencia a necessidade da condição de intercâmbio material entre o homem e a natureza:

O processo de trabalho, que descrevemos em seus elementos simples e abstratos, é atividade dirigida com o fim de criar valores-de-uso, de apropriar os elementos naturais às necessidades humanas; é condição necessária do intercâmbio material entre o homem e a natureza; é condição natural eterna da vida humana, sem depender, portanto, de qualquer forma dessa vida, sendo antes comum a todas as suas formas sociais. Não foi por isso necessário tratar o trabalhador em sua relação como outros trabalhadores. Bastaram o homem e seu trabalho, de um lado, a natureza e seus elementos naturais, do outro. O gosto do pão não revela quem plantou o trigo, e o processo examinado nada nos diz sobre as condições em que ele se realiza, se sob o látego do feitor de escravos ou sob o olhar ansioso do capitalista, ou se o executa Cincinato levando algumas jeiras de terra ou selvagem ao abater um animal bravio com uma pedra ${ }^{4}$.

A relação íntima que se estabelece entre homem e natureza define os elementos de trabalho como Marx os classifica:

1) A atividade humana adequada a um fim, isto é o próprio trabalho;

2) A matéria a que se aplica o trabalho, o objeto de trabalho;

\footnotetext{
Não se trata aqui das formas instintivas, animais, de trabalho. Quando o trabalhador chega ao mercado para vender sua força de trabalho, é imensa a distância histórica que media entre sua condição e a do homem primitivo com sua forma ainda instintiva de trabalho"(op. cit. p. 202). Não fica claro que o "estágio" da humanidade que se refere Marx com a expressão "homem primitivo". Se o trabalho define a diferença do homem para o animal, quando houver homem haverá trabalho(sob a forma humana).

${ }^{3}$ Op. cit. p. 205.

${ }^{4}$ Op. cit. p. 208 e 209.
}

3) Os meios de trabalho, o instrumento de trabalho 5 .

Marx sintetiza essa relação homem e natureza num processo de trabalho vivo:

O trabalho vivo tem de apoderar-se dessas coisas, de arrancá-las de sua inércia, de transformá-las de valores-de-usos possíveis em valores-de-usos reais e efetivos. O trabalho, com sua chama, delas se apropria, como se fossem partes do seu organismo, e de acordo com a finalidade que o move lhes empresta vida para cumprirem suas funções. O processo de trabalho, a atividade do homem opera uma transformação subordinada a um determinado fim, no objeto sobre que atua por meio do instrumental de trabalho. O processo extingue-se ao concluir-se o produto. $\mathrm{O}$ produto é um valor-de-uso, um material da natureza adaptado às necessidades humanas através da mudança de forma. O trabalho está incorporado ao objeto que atuou'.

Deste entendimento, considera-se essencial para o conhecimento da ontológica do ser social a condição humana, que consiste em entender o papel da práxis em sentido objetivo e subjetivo na relação de trabalho e como essa relação ou a sua negação passa a se configurar onde a pobreza tem se mostrado crescente.

\section{Processo sociometabólico entre Trabalho e Sociedade}

A história mostra como lembrou Marx há mais de um século e meio, que até hoje os seres humanos vivem a pré-história das sociedades de classes, em que grupos ou classes dominantes escravizam ou alienam os demais grupos ou classes. Pode se dizer, uma história onde o humano está cindido. E como diria Nosella (1997), o significado dominante que assume o trabalho na história das humanidades e que ainda perdura é o de tripalium (instrumento de três partes utilizado para torturar).

D'Angelis (2001) complementa dizendo que o trabalho em nenhuma sociedade humana, é função apenas do interesse do indivíduo. Onde quer que seja, tem repercussões sociais: seja pelo acúmulo de conhecimento; pela contribuição material e

\footnotetext{
${ }^{5}$ Op. cit. p. 202.

${ }^{6}$ Op. cit. p. 207 e 209.
} 
cultural do grupo ou comunidade; à manutenção à forma de organização social, econômica e política (D’ANGELIS, 2001, p.4).

Desde o século XVIII, em que quase todas as sociedades, o trabalho - como descreve Frigotto (2002) - vem sendo regulado pelas relações sociais capitalistas. Trata-se de um modo de produção social da existência humana que se foi estruturando em contraposição ao modo de produção feudal, mediante o surgimento da propriedade privada dos meios e instrumentos de produção ${ }^{7}$. Para constituir-se, todavia, necessitava - além do surgimento da propriedade privada - da abolição da escravidão, sendo que era essencial dispor de trabalhadores duplamente livres, ou seja, de não-proprietários de meios e instrumentos de produção e tampouco de propriedades de senhores ou donos (FRIGOTTO, 2001, p. 16).

É dessa relação social assimétrica que se constituem as classes sociais fundamentais: por um lado o capitalista detentor dos meios de produção, e por outro lado o não-proprietário - os trabalhadores que submetidos a alienar sua força de trabalho para que possam sobreviver.

Em uma sociedade capitalista industrial como a nossa, D'Angelis volta exemplificar como os interesses tanto individuais quanto coletivos, todos contribuem para a reprodução desta mesma sociedade onde se geram.

Em uma sociedade capitalista industrial como a nossa, montar uma fábrica de automóveis, construir uma hidroelétrica, abrir uma escola, garantir a existência de emissoras de televisão, publicar horóscopo ou criar uma congregação religiosa evangélica, nem sempre são vistas como atividades orientadas a um mesmo fim. Ainda que cada uma delas seja elevada a efeito, do ponto de vista de seu empreendedor, como uma atividade que atende a interesses individuais do sujeito ou de um pequeno grupo (D'ANGELIS, 2004, p. 4).

Na perspectiva marxista de "trabalho produtivo" o modelo capitalista com o objetivo de produzir lucro - não encontra espaço e função na interpretação das sociedades indígenas enquanto estejam

\footnotetext{
${ }^{7}$ É comum confundir como capitalista alguém que tenha apartamento próprio, carro próprio e/ou alguma propriedade da qual tira a sua sobrevivência. Na verdade, na medida em que tem apenas valor de uso e de subsistência não pode ser entendida como propriedade capitalista. Propriedade, meios e instrumentos de produção capitalista são aqueles cujo fim é a exploração de outrem para acumular mais riqueza e mais capital.
}

isoladas, ou seja, marginalizadas ao sistema capitalista. Relembrando que esse modelo capitalista não faz nenhum tipo de diferenciação antropológica, e como tal, serve apenas para interpretar a economia de uma sociedade, e não a sociedade.

Esse não entendimento interpretativo das diferentes sociedades que se apresentam e que formam a sociedade por força do capitalismo se apresenta na qualidade de modo específico de controle sociometabólico.

Mészáros (2002) explica essa relação ao afirmar que: o capital é um modo de controle que se sobrepõe a tudo o mais, antes mesmo de ser controlado.

Na qualidade de modo específico de controle sociometabólico, o sistema docapital inevitavelmente também se articula e consolida como estrutura de comando singular. As oportunidades de vida dos indivíduos sob tal sistema são determinadas segundo o lugar em que os grupos sociais a que pertencem estejam realmente situados na estrutura hierárquica de comando do capital.

Sob um de seus principais aspectos, esse processo de sujeição assume a forma da divisão da sociedade em classes sociais abrangentes, mas irreconciliáveis apostas entre si em bases objetivas e, sob o outro dos aspectos principais, a forma da instituição do controle político total. Ela vem da consolidação insuperável, sob o domínio do capital, de que a sociedade deva se estruturar de maneira antagônica e específica, já as funções de produção e controle do processo de trabalho devem estar radicalmente separadas uma da outra e atribuídas a diferentes classes de indivíduos (MÉSZÁROS, 2002, p. 98-99).

Clastres quando fala do Anti-Édipo ${ }^{8}$ rejeita a ação de troca enquanto "princípio" fundador da sociedade. Em seu livro sobre a filosófica da chefia indígena - uma crítica cuidadosamente sinuosa a um texto de Lévi Strauss que pensava a chefia como resultado de uma troca recíproca entre o líder e o grupo - já havia sugerido que a concepção indígena do poder implicava ao mesmo tempo uma afirmação

\footnotetext{
${ }^{8}$ A obra Anti Édipo (1972) e Mil Platôs (1980), onde as ideias de Clastres são utilizadas como um dos principais elementos para a montagem de uma antropologia radicalmente materialista, isto é, não humanista e não representacionalista, muito diversa do espiritualismo político que transpira das interpretações fenomenológicas da obra clasteriana.
} 
da reciprocidade e sua negação, ao colocar o lugar do chefe fora de sua esfera - na posição, precisamente de devedor unilateral perpétuo do grupo sem retirar da troca seu valor sociológico fundante. Ao deslocar-se da relação intracomunitária para a relação intercomunitária, a negação da troca se converte na essência mesma do socius primitivo. A sociedade primitiva é "contra a troca" pelas mesmas razões que é contra o Estado: porque ela deseja a autarquia e a autonomia - porque ela "sabe" que toda a troca é uma forma de dívida, isto é, de dependência, mesmo que recíproca (CLASTRES, 2011, p. 334-335).

\section{Sociedades que vivem sem acumular}

Subjugar as sociedades que não se organizam em função da realização de lucro pela exploração do trabalho não são, por causar isso, sociedades sem trabalho ou sem trabalho produtivo.

É preciso identificar qual é o leit motiv dessas sociedades, ou seja, o que é o motor que as coloca em andamento, prejulgamo-las e olhamo-las a ideia difundida de que as sociedades indígenas estariam "estagnadas" no tempo, ou vivem um tempo cíclico e "sem futuro".

E, por mais que o Estado tenha reconhecido os direitos indígenas na Lei $\mathrm{n}^{\mathbf{0}} 6.001$, de 19 de dezembro de 1973 e no Art. $1^{\circ}$, inciso IV - assegurar aos índios a possibilidade de livre escolha dos seus meios de vida e subsistência. Pergunta-se: Assegurar ao índio sua livre escolha dos seus meios de subsistência seria presenciar de forma tranquila as tribos Guarani e Kaingang saírem de seu habitat, tendo que alienar sua força de trabalho as formas estabelecidas pelo capitalismo?

Em estudos de Clastres (1988), A sociedade contra o Estado, pode ser respondido: "Se entendermos por técnica o conjunto dos processos de que munem os homens, não para assegurar o domínio absoluto da natureza (isso só vale para o nosso mundo e seu insano projeto cartesiano cujas consequências ecológicas mal começadas a medir), mas para garantir um domínio do meio natural adaptado e relativo às suas necessidades, então não mais podemos falar em inferioridade técnica das sociedades primitivas; elas demonstram uma capacidade de satisfazer suas necessidades pelo menos igual àquela de que se orgulha a sociedade industrial e técni- ca. Isso equivale a dizer que todo o grupo humano chega a exercer pela força o mínimo necessário de dominação sobre o meio que ocupa" (CLASTRES, 1988, p. 133 -134).

O mesmo autor mostra o preconceito contra as sociedades indígenas com base na concepção capitalista de "trabalho", expressa sobre o conceito de "economia de subsistência". Isso esclarecido, Clastres ainda questiona: cabe objetar o bom senso, para que serve um mercado, se não há excedentes?

Ora, as ideias de economia de subsistência contem em si mesmas a afirmação de que, se as sociedades primitivas não possuem excedentes, é porque são incapazes de fazê-lo, inteiramente ocupadas que estariam em produzir o mínimo necessário à sobrevivência, à subsistência.

Dessa condição humana que constitui o indígena, aos olhos do branco, a imagem antiga, sempre de ineficaz, da miséria dos selvagens. E, a fim de explicar essa incapacidade das sociedades primitivas de sair da estagnação de viver o dia-a-dia, dessa alienação permanente na busca de alimentos, invoca-se o subequipamento técnico a inferioridade tecnológica.

Já o homem branco, que se insere na lógica do capital, que precisa acumular para sobreviver, não consegue entender como o indígena apenas produz o necessário para sua sobrevivência.

Clastres pergunta então: o que ocorre na realidade?

Se entendermos por técnica o conjunto dos processos de que se unem os homens, não para assegurar o domínio absoluto da natureza (isso só vale para o nosso mundo em seu insano projeto cartesiano cujas consequências ecológicas mal começamos a medir), mas para garantir um domínio do meio natural adaptado e relativo às suas necessidades, então não podemos mais falar em inferioridade técnica das sociedades primitivas: elas demonstram uma capacidade de satisfazer suas necessidades pelo menos igual àquela de que se orgulha a sociedade industrial e técnica. Isso equivale dizer que todo o grupo humano chega a exercer, pela força, o mínimo necessário de dominação sobre o meio que ocupa (CLASTRES, 1974, p. 4).

E, como disse Clastres, "existe aí um preconceito tenaz, curiosamente co-extensivo à ideia contraditória e não menos corrente de que o selvagem é 
preguiçoso. Se em nossa linguagem popular diz-se 'a trabalhar como um negro"' na América do Sul, por outro lado, diz-se 'vagabundo como um índio'. Então das duas uma: ou o homem das sociedades primitivas, ameríndias e outras vive em economia de subsistência e passa quase todo o dia à procura de alimento, ou não vive em economia de subsistência e pode portanto se proporcionar lazeres prolongados fumando em sua rede." Os índios, efetivamente, só dedicam pouco tempo àquilo a que damos o nome de trabalho ${ }^{10}$. E apesar disso não morriam de fome. Os cronistas da época são unânimes em descrever a bela aparência dos adultos, a boa saúde das numerosas crianças e variedade de recursos alimentares (CLASTRES, 1974, p. 6 e 7).

Ainda nos estudos de Clastres revela que a economia de subsistência das tribos indígenas não implicava de forma alguma a angustiosa busca, em tempo integral, de alimento. Uma economia de subsistência é, pois, compatível com uma considerável limitação do tempo dedicado às atividades produtivas. Isso foi verificado com as tribos sul-americanas de agricultores, como os Tupi-Gurani, cuja ociosidade irritava igualmente os franceses e os portugueses. Portanto, a vida econômica desses índios baseava-se sobre tudo na agricultura, e, acessoriamente, na caça, na pesca, e na coleta.

No caso desse estudo, com os Kaingang e Guarani da reserva de Mangueirnha sudoeste do Paraná, Mota (1994) já expunha a ideia da região como um imenso vazio demográfico construída por geógrafos que descreviam sobre a ocupação das terras paranaenses nas décadas de 30 a 50 , por meio da historiografia universitária produzida no Paraná. Este espaço, habitado por comunidades indígenas, passa a ser projetado como um espaço vazio improdutivo, pronto a ser ocupado pela economia nacional produtiva (MOTA, 1994, p. 9 -19).

\footnotetext{
${ }^{9} \mathrm{O}$ autor fala da França, vale lembrar.

${ }^{10} \mathrm{O}$ próprio Clastres cita resultados de pesquisas a esse respeito: "quer se trate de caçadores-nômades do deserto do Kalahari ou de agricultores sedentários ameríndios, os números obtidos revelam uma média do tempo diário de trabalho inferior a quatro horas por dia. J. Lizot, que vive há muitos anos entre os índios Yanomani da Amazônia venezuelana, estabeleceu cronometricamente que a duração média do tempo que os adultos dedicam todos os dias ao trabalho, incluídas todas as atividades mal ultrapassa três haras" (Clastres, 1988, p. 136, destaque do autor). "Isso significa - diz Clastres, em outra passagem - que as sociedades primitivas dispõem, se assim o desejarem, de todo o tempo necessário para aumentar a produção de bens materiais" (Clastres, 1988, p. 198:137).
}

O norte e o oeste paraense da metade do século XIX em diante, com suas florestas, rios, minérios, terras roxas, climas amenos, aguardaram a sua internalização no processo de produção da sociedade industrial. Como na literatura da conquista americana, a literatura que faz a apologia da colonização paranaense trata a natureza de forma hostil, como um perigo a ser vencido numa longa jornada de lutas e sacrifícios, pois na missão de domar matas virgens é necessário, sobretudo, estoicismo (MOTA, 1994, p.10).

São esses estudos primários que revelam o processo histórico dessas culturas, bem antes já submetidas à negação de seus territórios como meio subsistências do índio.

É evidente que os índios que lá viviam não estavam imunes a todo este contexto de violência e dominação dos grupos hegemônicos sobre posseiros e colonos, e também de firme resistência popular empreendida. Os índios Kaingang e Guarani do sudoeste paranaense foram igualmente afetados pela ação predatória dos mesmos grupos que tomavam à força e especulavam as terras dos seus vizinhos agricultores brancos sem capital, nem prestígio político.

Nesses tempos de "progresso" a terra dos índios foi alvo de negociata perpetrada pelo Governo do Estado do Paraná com anuência do Ministério da Agricultura e do seu órgão subordinado o Serviço de Proteção ao Índio em 1949, sob a alegação de regularizar as terras destinadas aos índios e com a finalidade de delimitar as áreas indígenas no Paraná.

Pode-se afirmar que ao produzir uma segunda natureza (o vazio geográfico) no norte do Paraná, o capitalismo estava produzindo um novo espaço geográfico, próprio à sua atuação e diferente do espaço tradicional das comunidades indígenas.

Este processo de ocupação das terras indígenas revelam as influências culturais e legislativas que as tribos receberam e, involuntariamente, incorporaram na sua história. A própria delimitação do espaço da aldeia das tribos Guarani e Kaingang (figura 1) cerceou a apropriação dos índios dentro de um espaço que antes não era limitado.

Tais movimentos históricos conduzem a um processo de territorialização do espaço indígena, podendo resignificar o sentido de pertencimento do índio com a terra, por justamente impor modos e até onde se pode ocupar. Neste sentido é que o estudo 
explora, se de fato a história decalcou seus traços nas tribos Guarani e Kaingang.

\section{Sociedades e o Estado: para quem se legisla?}

Muito embora em 1891 a Constituição Federal que transfere o domínio das terras devolutas que até então eram do domínio imperial, Darcy Ribeiro (1996) revela de suas fontes históricas que subsiste naturalmente o direito às terras possuídas em termos legalmente definidos nos regimes anteriores, principalmente as dos índios. Contudo, muitos estados incorporaram ao seu patrimônio as terras de legítima propriedade indígena.

A posse de um território tribal é condição essencial à sobrevivência dos índios: ela opera como barreira à interação e à incorporação (Ribeiro, 1996), permitindo ao índio refugiar-se num espaço que lhe garanta sua subsistência, facultando-lhe escapar aos que, de outro modo, o compeliram a incorporar-se à massa de trabalhadores (Ribeiro, 1996, p.118).

Casos concretos observados no Brasil revelam tribos que perderam suas terras e foram levadas a perambular pelas fazendas particulares como reservas de mão-de-obra (Ribeiro, 1996). Na prática, seu despreparo para as "tarefas civilizadas" a conservação de ideias e motivações da cultura original e outros fatores, os conduzem a tamanho desgaste que estariam fatalmente condenados ao extermínio se não fossem recolhidos a um posto de proteção.

Então cabe perguntar, porque Clastres teria escrito sobre as sociedades sem estado? Clastres entende que:

As sociedades primitivas são sociedades sem Estado: esse julgamento de fato, em si mesmo correto, na verdade dissimula uma opinião, de valor, que prejudica então a possibilidade de construir uma antropologia política com ciência rigorosa. $\mathrm{O}$ fato que se enuncia é as sociedades primitivas estão privadas de alguma coisa. - O Estado que lhes é, tal como a qualquer outra sociedade - a nossa, por exemplo, - necessária. Essas sociedades são, portanto incompletas. Não exatamente verdadeiras sociedades - não são policiadas, e subsistem na experiência tal vez dolorosa de uma falta - falta do Estado que elas tentariam, sempre em vão, suprir. Ainda existe um equivoco maior no imaginário social, do "homem civilizado" aponta Clastres:
"De um modo mais ou menos confuso, é isso mesmo o que dizem as crônicas dos viajantes ou trabalhadores dos pesquisadores: não se pode imaginar a sociedade sem estado, o Estado é o destino de toda a sociedade. Descobre nessa abordagem uma fixação etnocêntrica tanto mais sólida quanto é ela, o mais das vezes, inconsciente. [...] cada um de nós traz efetivamente em si, interiorizada como a fé do crente, essa certeza, de que, a sociedade existe para o Estado" (CLASTRES, 1974, p. 3).

O direito do índio a terra em que vive, embora amparado por copiosa legislação que data dos tempos coloniais, jamais se pôde praticar de fato. Ainda hoje continua impreciso, dando margem a perturbações de toda ordem (RIBEIRO, 1996, p. 218).

Ribeiro (1996) relembra que, após quatro séculos de uma falsa proteção provisória, os índios foram despojados de quase todas as terras que tinham valores passíveis de exploração econômica. $\mathrm{O}$ autor demonstra que a realidade dos programas que tentam inserir o índio nos moldes de produção civil, embora reconheçam a potencialidade do índio, descartam alguns fatores:

$\mathrm{O}$ vigor do conservadorismo dos grupos indígenas, sua tenaz resistência à mudança e a força do sentimento de identificação tribal que leva estes grupos étnicos a lutar para conservar sua identidade e sua autonomia;

A incapacidade da sociedade brasileira, particularmente das fronteiras de expansão, para assimilar grupos indígenas, proporcionando-lhes estímulos e atrativos para nela se dissolverem (RIBEIRO, 1996, p. 212).

Nesta cúmplice comunhão de Clastres (1988) e Ribeiro, no modo de interpretar o papel do Estado, Clastres diz: manter grupos numericamente pequenos e com autonomia local seria um importante recurso de que essas sociedades deliberadamente lançam mão para seus objetivos. Ainda completa:

$\mathrm{O}$ que se constata no mundo dos selvagens é um extraordinário esfacelamento das 'nações', tribos, sociedades em grupos locais que tratam cuidadosamente de conservar sua autonomia no seio do conjunto do qual fazem parte, com o risco de concluir alianças provisórias com seus vizinhos, se as circunstancias _ guerreiras em particular _o exigem. Essa atomização do universo tribal é certamente um meio eficaz de 
impedir a constituição de conjuntos sócio-políticos que integram os grupos, e mais além um meio de proibir a emergência do Estado que, em sua essência é unificador (CLASTRES, 1974, p. 9).

Não são, pois, sociedades que simplesmente 'sofrem' os imperativos do tempo e da história. São sociedades politicamente engajadas em um projeto e um esforço de preservação das formas de relacionamento e organização social que historicamente produziram. Pode-se dizer que, no limite, são sociedades engajadas em um projeto cuja principal razão de ser é impedir o surgimento do trabalho alienado.

O Estado em sua máxima posição se distância muito mais na compreensão do modo de vida dessas sociedades. É como esclarece Mészáros (2002):

Como necessidade igualmente inevitável sob o sistema do capital, não basta que se imponha a divisão social hierárquica do trabalho, como relacionamento determinado de poder, sobre os aspectos funcionais/ técnicos do processo de trabalho. É também forçoso que ela seja apresentada como justificativa ideológica absolutamente inquestionável e pilar de reforço da ordem estabelecida. [...] com relação a sua determinação mais profunda, o sistema do capital é orientado para a expansão e movido pela acumulação. Essa determinação constitui, ao mesmo tempo, um dinamismo antes inimaginável e uma deficiência fatídica. Nesse sentido Mészáros aponta o sistema de controle sociometabólico, o capital é absolutamente irresistível e enquanto conseguir extrair e acumular trabalho excedente - seja na forma econômica direta seja forma basicamente política no decurso da reprodução expandida da sociedade considerada (MÉSZÁROS, 2002, p. 99 -111).

Disso, resulta a crise estrutural do capital, e seus contingentes destrutivos avançam de forma extrema e incontrolável, fazendo com que se promova a autodestruição, tanto para este sistema reprodutivo social excepcional, em si, como para a humanidade em geral.

E, ao falar da humanidade, são destacadas as minorias étnicas, as quais esse mesmo Estado que as submetê-las as mesmas condições hierárquicas pela qual a desigualdade estruturalmente é reforçada, ou seja, conciliada com a mitologia de "igualdade e liberdade" - "livre opção econômica" e "livre escolha política" sem hesitação ou medo de incoerência nos contextos ideológicos mais reveladores, para justificar a desigualdade socialmente criada e reforçada em nome da "desigualdade natural".

E conclui Clastres (1974), hipotética, essa modificação da base econômica é ainda mais impossível. Para que, numa sociedade, o regime de produção se transforme no sentido de uma maior imensidade de trabalho que visa a uma produção acrescida de bens, é necessário ou que os homens dessa sociedade desejem essa transformação de seu gênero de vida tradicional, ou que, mesmo não desejando, eles se vejam obrigados por violência externa.

O Estado, dizem, é o instrumento que permite à classe dominante exercer sua dominação violenta sobre as classes dominadas. Para que haja o aparecimento do estado, é necessário, pois, que exista antes decisão da sociedade em classes sociais antagônicas entre si por relação de exploração. Por conseguinte, a estrutura da sociedade - a divisão da sociedade em classes - deveria preceder a emergência da máquina estatal.

Clastres aponta a fragilidade dessa concepção puramente instrumental do Estado. Se a sociedade é organizada por opressores capazes de explorar os oprimidos, é que essa capacidade de impor a alienação repousa sobre o uso de uma força, isso é sobre o que faz da própria substância de um Estado "monopólio da violência física legitima”.

Fica então a pergunta. A que necessidade responderia desde então a existência de um Estado, uma vez que sua essência - a violência - é imanente à divisão da sociedade e que é dada a emancipação na opressão exercida de um grupo social sobre outros? (CLASTRES, 1974, p. 14).

Parte desse questionamento encontra resposta neste texto no relato das entrevistas com os índios das tribos Guarani e Kaingang deixados pelos índios Papa Mirin, Muhte e Gãvoj.

\section{O trabalho indígena: por que ter que sair da aldeia?}

Este item trata do relato realizado na pesquisa de campo junto à comunidade Mbyá-Guarani de Palmeirinha, localiza-se na Reserva Indígena de Mangueirinha no estado do Paraná, conforme mapa 01. Possui uma área de $16.375,00 \mathrm{ha}$, abrangendo 
os municípios de Chopinzinho, Coronel Vivida e Mangueirinha (MPF, 2005). A reserva possui uma população de 1.830 indígenas, divididos nas etnias Guarani e Kaingang, tendo acesso pela BR 373. É considerada uma das maiores reservas naturais de araucárias do mundo, fazendo parte de uma área estratégica para conservação da biodiversidade (ITCG, 2010).

Mapa 1: Localização da Reserva Indígena de Mangueirinha

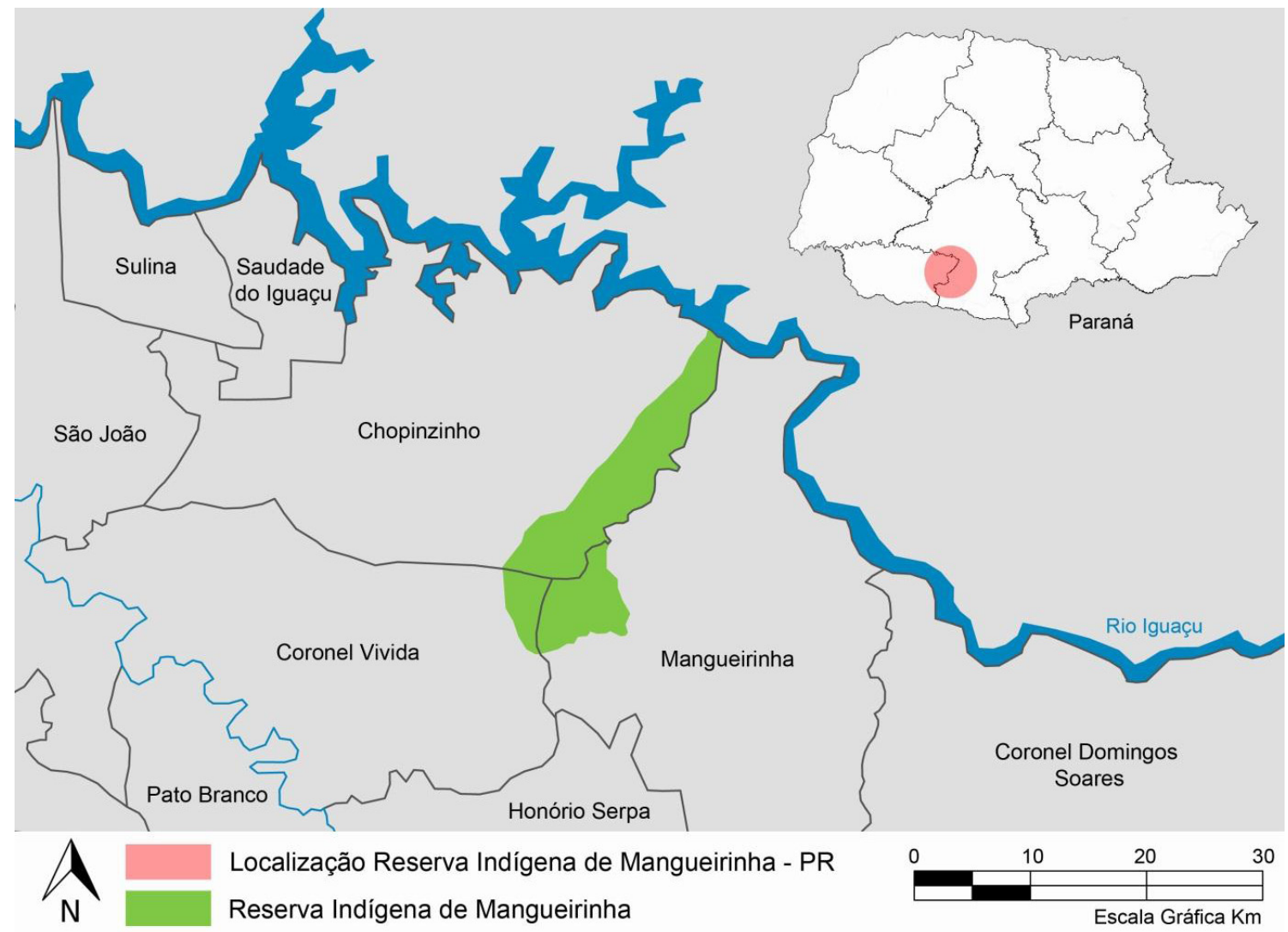

Fonte: Adaptação sobre mapa territorial do sudoeste do Paraná, AMSOP (2012).

Partindo dos questionamentos levantados: Como as sociedades indígenas entendem o trabalho em relação ao que nós definimos como trabalho? $\mathrm{E}$, em que reside a diferente consideração sobre o trabalho nas sociedades indígenas em contraposição às sociedades capitalistas? As visitas foram do mês de fevereiro a agosto de 2013, realizadas quatro idas à aldeia.

Em conversa com o índio Luis Boantin, Papa Mirin, índio guarani e com as índias Tereza Eufrazio, Gãvoj e Antonia Eufrazio, Muhte, indias Kaingang, os quais durante as conversas informaram sobre seus modos de vida e costumes e como concebem o trabalho e sua relação ao modo capitalista de produção.
Hoje tanto na aldeia Guarani como na Kaingang muitos indígenas encontram-se trabalhando fora da aldeia para empresas como frigoríficos, indústrias madeireiras e indústrias de eletrodomésticos localizadas na cidade de Pato Branco e cidades vizinhas.

Dados obtidos em agosto de 2013 pelas empresas Frango Seva, a qual emprega atualmente 19 homens e 25 mulheres, a empresa Atlas indústria de Fogões Petricoski, emprega 9 homens e 2 mulheres e a Companhia de Saneamento do Paraná SANEPAR emprega 1 homem, totalizam-se, 29 homens e 27 mulheres.

Ambas as empresas fornecem o transporte coletivo para o deslocamento dos índios no trajeto da reserva de Mangueirinha à cidade de Pato Branco Paraná. 
Diante desta realidade, foi selecionada uma entrevistas para este estudo, a fim de saber como se dá a relação de trabalho fora da aldeia.

Ao perguntar ao Papa Mirin por que resolveu trabalhar para a Companhia de Saneamento do Paraná SANEPAR, ouvimos: Papa Mirin - Por que o que se pranta na lavoura num ano dá bem, as prantas pra compra as coisa pra família. Perguntado se você pudesse não ter que trabalha para a SANEPAR, faria lavoura ou artesanato?

Papa Mirin - A roça não da o alimento como era. Quem manda a semente é a prefeitura, a semente que manda é fraca. Eles dão a semente, mas não o adubo, a ureia o veneno a prefeitura não compra, dai não dá a pranta, não nascem bem. A roça de mandioca, essa dá, os vizinhos arrumam as pranta e a gente reparte entre nóis.

Da fala de Papa Mirin, é possível identificar claramente o papel antagônico que Estado exerce sobre a força de trabalho com as sociedades indígenas.

Quando Papa Mirin se refere, [...] o que se pranta na lavoura num ano dá bem. Deixa evidente o uso da terra pelo índio sob a influência de gerenciamento de programas e políticas públicas de manejo e cultivo da terra que o Estado propõe. Tais práticas tem se revelado insuficiente para produzir alguns tipos de cultivo, conforme registros observados na pesquisa de campo sobre as lavouras em terras indígenas da reserva em estudo.

Pouco existe sobre a forma primitiva (original) que o índio trabalha a terra (preparar o terreno, a derrubada e queimadas) em pequenas roças, o índio o faz, apenas ao que corresponde à subsistência da tribo, do que vai ser consumido em uma determinada estação. Por outro lado, o Estado sob o ponto de vista capitalista, interpreta a cultura indígena colocando-a em condições de trabalho impotente, provocando especiocídio, um extermínio de uma espécie, do seu modo ainda de vida comunal representados em sua cultura.

Isso demonstra à necessidade igualmente inevitável sob o sistema do capital, não basta que se imponha a divisão social hierárquica do trabalho, como relacionamento determinado de poder, sobre os aspectos funcionais/técnicos do processo de trabalho. O modo impositivo de produzir a terra indígena na aldeia de Mangueirinha, forma mecanizada, "transformando" a roça em lavoura, uma prática antagônica a essência cosmológica que esses povos ainda demonstram ter em respeito à terra e aos animais.

Outro modo de dependência provocada pelo Estado é interpretada nas palavras de Papa Mirin ao dizer: [...] "Quem manda a semente é a prefeitura, a semente que eles manda é fraca. Eles dão a semente, mas não o adubo, a ureia o veneno, a prefeitura não compra, daí não dá a pranta, não nascem bem." Neste caso a prefeitura é um órgão do Estado, órgão de poder, poder que determina o que é "ideal no cultivo da terra" e por outro lado à própria natureza (a terra), que se não for mantida com insumos agrícolas não produz sementes geneticamente modificadas.

Um último fragmento de sua fala revela: [...] "A roça de mandioca, essa dá, os vizinhos arrumam as rama e a gente reparte entre nóis". A roça, o modo primitivo de cultivo de subsistência, revela a ontologia social da cultura do - índio - e sua intimidade e proximidade com trabalho artesanal, da sociedade primitiva, isso demonstrar que, por mais que os índios saibam que existe técnica mecanizada, muitos índios até "aderiram às técnicas do homem branco", mas a experiência não se apresenta tão exitosa, visto os relatos de Papa Mirin e o que pudemos observar em outras lavouras na aldeia.

O modo como os indígenas decidem pelo cultivo das plantas, do fazer da roça, em puxirão ou mutirão, está carregada significados de uma cultura que vem de gerações a gerações, a vida comunal entre estes povos, enquanto o que o modo de plantio do homem branco através da ceifadeira mecanizada, onde apenas um índio opera a máquina tende a contribuído no sentido, de desaparecer o modo de trabalho índio na sua relação com a natureza. Para o índio, não importa a extensão de uma lavoura, e sim, o sentido de fazer uma roça, a representação do trabalho coletivo e, não a o trabalho individual. $\mathrm{O}$ índio não concebe a terra da mesma forma como o homem branco, que espera dela apenas o lucro que uma lavoura vá lhe render, o índio pelo contrario, tem uma relação viva com seu habitat natural, uma compreensão cosmológica, de respeito pelos ciclos de cada estação e de cada lua.

Essa diferença também é descrita por D'Angelis (2001): 
A diferença está na finalidade do trabalho e na apropriação dos seus resultados. Mesmo quando um caçador não pode comer da carne do animal que ele próprio caçou (por um intermédio social, ou tabu, comum em sociedades caçadoras), ele sabe que sua caça mantem sua sociedade funcionando e é parte de suas obrigações com seus parentes que, por sua vez, também lhe garantirão carne de caça para comer, daquela que eles cacem (D'ANGELIS, 2001, p. 13).

Numa sociedade indígena não alterada pela convivência com a sociedade não-indígena, ninguém se sente explorado em seu trabalho, porque não há situação em que alguém se aproveitando do trabalho dos demais. Também não se coloca a alternativa do "não-trabalho", porque não se coloca a alternativa do não-comer, do "não-morar", etc.

$\mathrm{Na}$ continuidade da conversa com foi perguntado: Se você pudesse sobreviver da caça, da pesca, da roça, você preferia trabalha na aldeia com isso?

Papa Mirin - Procuraria outro emprego, porque com a lida da aldeia não da mais pra compra as coisa, falta. A ropa nóis ganha do irmão que mora em no Rio de Janeiro em Porati Mirim. Eu trabalharia no frigorifico, nas fábricas, na Frango Seva, ou na Atlas, nas fábrica de Pato Branco. Ao apontar que: [...] com a lida, na terra da aldeia, não da mais pra compra as coisa, falta. A essa resposta revela fotos históricos de exploração e desmatamento da terra pelos brancos nas décadas de 30 e 50 no sudoeste paranaense.

O índio ao se deparar com um ecossistema comprometido pelo desmatamento, resta-lhe trabalhar para do domo do capital e submeter-se ao julgamento de concepções errôneas como aponta Clastres: [...] "mera economia de subsistência", "lazer limitado, salvo em circunstâncias excepcionais", "busca incessante de comida", recursos naturais, "pobres e relativamente incertos", "ausência de excedente econômico", máximo de energia de um máximo de pessoas" - isto é a opinião média antropologia sobre o trabalho (caça e coleta), das sociedades primitivas (CARVALHO, 1978, p. 8).

Dessas inquietações e a realidade revelada da aldeia e como estão vivendo os índios Guarani e Kaingang e saindo da aldeia em busca de trabalho na cidade, Clastres (1988), descreve que: manter grupos numericamente pequenos e com autonomia local seria um importante recurso de que essas sociedades deliberadamente lançam para seus objetivos e previne seu esfacelamento.

O que se contata no mundo dos selvagens é um extraordinário esfacelamento das 'nações', tribos, sociedades em grupos locais que tratam cuidadosamente de conservar sua autonomia no seio do conjunto do qual fazem parte, com o risco de concluir alianças provisórias com seus vizinhos, se as circunstâncias - guerreiras em particular o exigem. Essa atomização do universo tribal é certamente um meio de impedir a constituição de conjuntos sócio-políticos que integram os grupos locais, e, mais além de um meio de proibir a emergência do Estado que, em sua essência é unificador (CLASTRES, 1988, p. 148).

Perguntado se havia mais índios trabalhando na cidade, Respondeu: Papa Mirin - Sim, tanto indios Guarani como indios Kaingang que trabalhão na Seva e na Atlas. Eles levantam às 4 horas da manhã e vão de onibus pra trabalha em Pato Branco e volta pra aldeia às $19 \mathrm{~h}$ e 30min. todo dia, eles recebem um salário de 700,00 a 800,00 real no mês. Daqui dos Guarani tem uns 12 indio trabalhando nas fábricas.

A forma contratual para estes indígenas estaria sendo cumprida segundo o que determina o artigo 16 do Estatuto do índio?

Art. 16. Os contratos de trabalho ou de locação de serviços realizados com indígenas $[\ldots] \S 2^{\circ} \mathrm{Em}$ qualquer caso de prestação de serviços por indígenas não integrados, o órgão de proteção ao índio exercerá permanente fiscalização das condições de trabalho, denunciando os abusos e providenciando a aplicação das sanções cabíveis.

Destas repostas é possível interpretar a forma que os índios tanto Guarani como Kaingang vêm mudando o modo de vida, atendendo de modo servil ao Estado segundo Carvalho (1978):

O Estado, que congregava grupos primitivos de comunidades pertencentes a uma mesma tribo com o único objetivo de salvaguardar seus interesses comuns e para se proteger de seus inimigos exteriores, adquire a partir daí a função de manter, pela força as condições de existência e de domínio da classe dirigente contra a classe submetida. (CARVALHO, 1978, p. 127). 
A migração de indígenas da aldeia para a cidade em busca de trabalho se cumpre no desejo do Estado, que age como um desporá ao desprover o trabalho indígena em seu território, a falta de orientação e de um projeto mais amplo, um projeto assistido numa constante, sobre políticas de manejo correto de seus recursos naturais, e não de caráter assistencialista de gestões de governos. Uma vez que o Estado intervém nessas sociedades e seus projetos se mostram descontínuos, isso resulta na exploração dessas sociedades, onde o Estado é proprietário último do solo.

Figura 1: Imagens do filho Eliéu, karí Jekuepe com seu pai o índio Luiz, Papa mirin (ao centro), pesquisadora Marta Beatriz dos Santos Dall'Igna (à esquerda), agosto de 2013.

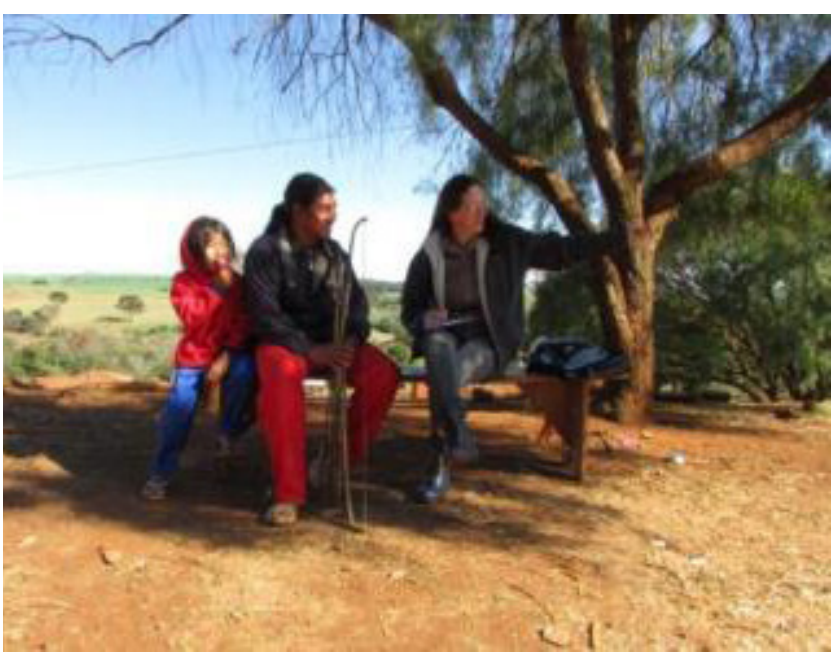

Fonte: fotografia Fabio Almeida.

Outros indígenas Kaingang também da reserva de Mangueirinha foram encontrados na rodoviária da cidade de Pato Branco Paraná vendendo artesanato no dia 04 de agosto de 2013 por volta das 19 horas. Durante a entrevista com as índias Tereza Eufrazio, Gãvoj de 70 e Antonia Eufrazio, Muhte de 54 anos e com ajuda de seus filhos que ali se encontravam foi possível registrar os depoimentos das índias sobre a forma de trabalho que exercem na cidade na venda do artesanato dos balaios.
Figura 2: Imagens da família de índios Kaingang na rodoviária da cidade de Pato Branco Paraná. Tereza Eufrazio, Gãvoj (à direita), Antonia Eufrazio, Muhte (ao centro), pesquisadora Marta Beatriz dos Santos Dall'Igna (à esquerda), agosto de 2013.

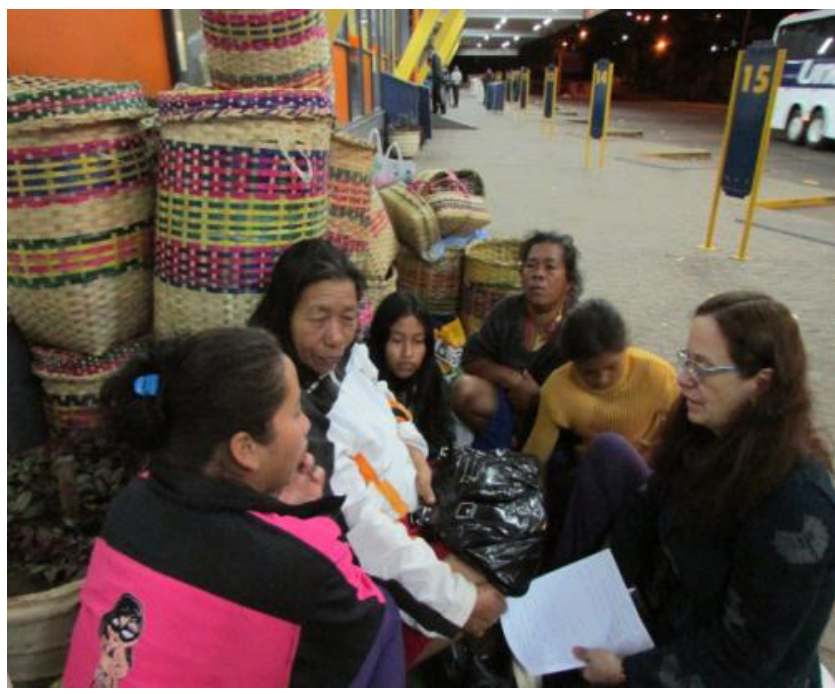

Fonte: fotografia Lucir Mendez da Silva Kafyr (índio Kaingang).

A foto acima é um dos casos de famílias indígenas que tem saído da aldeia no trabalho de vender os balaios. Costumam vir à cidade a cada dois meses. Deslocam-se com os cestos grupos de famílias que costumam vender o artesanato nas cidades vizinhas como Coronel Vivida e Pato Branco paraná.

Pesquisadora - Quanto à venda dos balaios na cidade, é boa? Gãvoj - - As veiz sai, sas veiz não, as veiz a gente vende por 20,00 ou 30,00 real, porque aqui na $B R$ vende poco. A gente vende se anda bastante, a gente acha custoso de posa (dormir), as veiz ele dexa fica as veiz ele não deixa posa aqui na rodoviária, lá em Coronel Vivida dexa posa. Eles não dão valor pra nóis, os índios estão rebaxados a gente fica sentido. Aqui a assistente social, se vê a gente, leva de volta pra aldeia, ela diz que não pode vende na cidade. A gente vende pra compra as coisa, ropa pros filho.

Clastres argumenta que, quando na sociedade primitiva, o econômico se deixa identificar como campo autônomo e definido, quando a atividade de produção se transforma em trabalho alienado, contabilizado e imposto por aqueles que vão tirar proveito dos frutos desse trabalho, é sinal de que a sociedade não é mais primitiva, tornou-se uma 
sociedade dividida em dominantes e dominados, em senhores e súditos, e de que parou de exorcizar aquilo que está destinado a matá-lo: o poder e o respeito ao poder (CLASTRES, 1988, p. 10).

Pesquisadora - Vocês preferem trabalhar para alguma empresa como alguns indígenas que estão trabalhando ou preferem continuar fazendo e vendendo o artesanato na cidade? Gãuvoj - É custoso o trabalho lá, por isso a gente prefere vende os balaios, melhor que trabalha de empregado dos otro, e é pra não deixa nossa cultura o sistema dos índios. Os home ficam na aldeia, busca a taquara no mato e prepara, fazendo o cesto grande, e nois vem pra cidade vende quando já precisa compra as coisa. Muhte - A gente vende aqui porque lá vende poco, a gente queria fica na aldeia, te coisa lá pra faze e fica lá vendendo, lá e melhor. Pesquisadora - O governo dá algum tipo de ajuda a vocês?

Muhte - Só uma cesta de comida, a Cesta Mesa Brasil, aquele vem uma vez por mês, não o governo não da pra todas as família, só umas.

Este último depoimento revela a estratégia do capitalismo globalizado pensada para a pobreza mundial. Diríamos falsa generosidade, mas que "alguma coisa está sendo feita", mas no limite da precariedade. No documento do BM na página 28 é evidente a dificuldade uma implementação eficaz do Projeto do Banco Mundial de apoio a programas Bolsa Família. (indígenas/quilombolas) de 10 de maio de 2004.

No entanto, a profusão de agentes de cadastramento dificulta o controle de que cada família seja cadastrada uma vez. A profusão de agentes de cadastramento dificultará ainda um outro aspecto, a da necessidade de treinamento especializado para a realização das entrevistas. Especialmente em áreas indígenas, que contam com sistemas de parentesco e de terminologia de parentesco diversos do que operamos, o agente de cadastramento tem que estar habilitado para registrar corretamente, $\mathrm{e}$ sem impor sua própria referência cultural, os residentes de um domicílio e as relações entre eles. (BANCO MUNDIAL - Apoio a Bolsa Família, 2004, p. 28).

A sentença bíblica de viver à custa de trabalho foi pronunciada contra nós. Escassez é a sentença decretada por nossa economia - e é também o axioma de nossa ciência econômica: a aplicação dos meios escassos contra fins alternativos, conforme as circunstâncias, para tirar a maior satisfação possível. E é precisamente a partir dessa vantagem que voltamos o olhar para os caçadores. Mas, se o homem moderno, com todas suas vantagens tecnológicas, ainda não conseguiu os meios, que chance possui esse selvagem desprotegido, com seu insignificante arco e flecha? Tendo equipado o caçador com impulsos burgueses e ferramentas paleolíticas, julgamos sua situação desesperadora (CARVALHO, 1978, p. 10).

\section{A urgência de uma estratégia de desenvolvimento}

A pesquisa de campo junto às comunidades indígenas revelou que há uma perspectiva diferente daquela da nossa sociedade a respeito do trabalho, e a forma como a origem do trabalho é registrada na aldeia da reserva de Mangueirinha no sudoeste paranaense entre as tribos Guarani e Kaningag. Muito embora, o fator que tem levado os índios a trabalhar na cidade, foi e continua sendo, que, parte de seu território, como a flora e a fauna já estejam comprometidas por estudo já mencionados por Mota (1994), formado um imenso vazio demográfico construído por geógrafos que descreviam sobre a ocupação das terras paranaenses nas décadas de 30 a 50 e a forte influência de fazendeiros interessados pela abundância da madeira existente na época. Este espaço, habitado por comunidades indígenas, passa a ser projetado como um espaço vazio improdutivo, pronto a ser ocupado pela economia nacional produtiva. Esses fatos, e o descontínuo de projetos e políticas públicas efetivas sobre a questão da terra, traduzem o porquê dos indígenas tem deixado de trabalhar na aldeia e migrarem para a cidade em busca de "trabalho".

Quanto à pergunta inicial. Como as sociedades indígenas entendem o trabalho em relação ao que nós definimos como "trabalho"? Pode-se dizer que para o índio, o trabalho mesmo quando árduo, não tem caráter de sacrifício ou punição, ao contrário da perspectiva bíblica (judaico-cristã) do trabalho como castigo, [...] "No suor do teu rosto comerás o teu pão, até que te tornes à terra; porque dela foste tomado; porquanto és pó e em pó te tornarás". 
(Gênesis), muito pelo contrário, muitas das sociedades indígenas explicitamente apresentam em seus modos de vida mais sagrado, o trabalho como um ato de celebração a vida, a tudo que a natureza e o homem juntos vão se apropriando e se modificando. O trabalho para esses povos provem dos ensinamentos dos pais, dos deuses, o trabalho se concebe como sagrado, são saberes passados de pai para filho, são saberes preciosos, por prevalecer conhecimentos passados de gerações a gerações. $\mathrm{O}$ trabalho toma sentido por estar vinculado ao ato de sabedorias sagradas que se manifestam em técnica que facilitam a vida do povo como: mitigar a fome, garantir a caça, a pesca, os frutos, o feitura dos adornos corporais, a pintura do corpo para os rituais e festejos, a seleção das ervas medicinais para a cura dos seus males.

Conclui-se então: essa realidade só será passível de mudanças se proporem trabalho para as diferentes sociedades indígenas, pensados do ponto de vista antropológico. $\mathrm{O}$ ser deve ser compreendido como totalidade concreta dialeticamente articulada em totalidades parciais. As estruturas construtivas do ser designam um complexo de complexos, e isso deve ser analisado em suas particularidades, neste caso, como culturas autóctones encontradas hoje na pobreza.

\section{Referências}

CASTRO, P. A. de S. Dissertação de Mestrado, Ângelo Cretã e a retomada das terras indígenas do Sul do Brasil., Curitiba, 30 de agosto de 2011.

CARVALHO, Edgard Assis. (Org.). Antropologia Econômica. Ed. Ciências Humanas LTDA, São Paulo. 1978.

CLASTRES, Pierre. A economia primitiva. In. Arqueologia da violência: ensaios de antropologia política. Trad. Carlos E.M. de Moura. São Paulo: Brasiliense, 1982.

A sociedade contra o Estado. Trad. T. Santiago. Rio de Janeiro: Francisco Alves, 1988. , 14-17, nov. 2001.

D'ANGELIS. R. Wilmar; VEIGA, Julia. O trabalho e a perspectiva das sociedades indígenas no Brasil. São Paulo, 2001.

ENGELS, Friedrich, Sobre o trabalho na transformação do macaco em homem. [1876]. In K. MARX \& F. ENGELS. Texto 1. São Paulo: Edições Sociais, p. 61-74.
FRIGOTTO, Gaudêncio; CIAVATTA, Maria. (orgs.). A experiência do trabalho e educação básica. Rio de Janeiro: DP\&A, 2002.

MARX, Karl. O capital: critica a economia e a política. Livro 1, volume 1, $3^{\text {a }}$ ed. , Ed. Civilização Brasileira S. A. Rio de Janeiro, 1975.

MÉSZÁROS, I. A. A ordem da reprodução sociometabólica do capital. In MÉSZÁROS. István. Para além do capita: rumo a uma teoria da tradição. São Paulo: Boitempo, 2002. p. 94-132.

MOTA, L. T. (1994), As guerras dos índios Kaingang: a história épica dos índios Kaingang no Paraná. EDUEM, Maringá, PR.

BM, BANCO MUNDIAL. Projeto do Banco Mundial de Apoio ao Programa Bolsa Família. (indigenas/ quilomboas), 10 de maio de 2004.

Submissão: 30/08/2013

Aprovação: 09/2014 